\title{
Size-partitioned phytoplankton carbon and carbon-to-chlorophyll ratio from ocean colour by an absorption-based bio-optical algorithm
}

Article

Accepted Version

Creative Commons: Attribution-Noncommercial-No Derivative Works 4.0

Roy, S., Sathyendranath, S. and Platt, T. (2017) Sizepartitioned phytoplankton carbon and carbon-to-chlorophyll ratio from ocean colour by an absorption-based bio-optical algorithm. Remote Sensing of Environment, 194. pp. 177-189. ISSN 0034-4257 doi: https://doi.org/10.1016/j.rse.2017.02.015 Available at https://centaur.reading.ac.uk/69297/

It is advisable to refer to the publisher's version if you intend to cite from the work. See Guidance on citing.

To link to this article DOI: http://dx.doi.org/10.1016/j.rse.2017.02.015

Publisher: Elsevier

All outputs in CentAUR are protected by Intellectual Property Rights law, including copyright law. Copyright and IPR is retained by the creators or other copyright holders. Terms and conditions for use of this material are defined in the End User Agreement. 


\section{CentAUR}

Central Archive at the University of Reading

Reading's research outputs online 


\section{Size-partitioned phytoplankton carbon and}

2 carbon-to-chlorophyll ratio from ocean-colour by

- Agriculture, Policy and Development, University of Reading, Whiteknights,

9 ${ }^{3}$ National Centre for Earth Observation, Plymouth Marine Laboratory, 
The standing stock of phytoplankton carbon is a fundamental property of oceanic ecosystems, and of critical importance to the development of Earth System models for assessing global carbon pools and cycles. Some methods to estimate phytoplankton carbon at large scales from ocean-colour data rely on the parameterization of carbonto-chlorophyll ratio, which is known to depend on factors such as the phytoplankton community structure, whereas other methods are based on the estimation of total particulate organic carbon (POC), and rely on the assumption that a known fraction of POC is made up of phytoplankton carbon. The carbon-to-chlorophyll ratio is also used in marine ecosystem models to convert between carbon and chlorophyll, a common requirement. In this paper we present a novel bio-optical algorithm to estimate the carbonto-chlorophyll ratio, and the standing stocks of phytoplankton carbon partitioned into various size classes, from ocean colour. The approach combines empirical allometric relationships of phytoplankton size structure with an absorption-based algorithm for estimating phytoplankton size spectra developed earlier. Applying the new algorithm to satellite ocean-colour data from September 1997 to December 2013, the spatio-temporal variations of carbon-to-chlorophyll ratio and phytoplankton carbon across various size classes are computed on a global scale. The average annual stock of phytoplankton carbon, integrated over the oceanic mixed-layer depth, is estimated to be $\sim 0.26$ gigatonnes, with the size-partitioned stocks of 0.14 gigatonnes for picoplankton, 0.08 gigatonnes for nanoplankton and 0.04 gigatonnes for microplankton. The root-mean-square error and the bias in the satellite-derived estimates of picoplankton carbon, when compared with corresponding in situ data, are found to be $36.23 \mathrm{mgC} \mathrm{m}^{-3}$ and $-13.53 \mathrm{mgC} \mathrm{m}^{-3}$, respec- 


\section{${ }_{43}$ Keywords}

44

45 picoplankton, nanoplankton, microplankton; phytoplankton size spectra.

\section{1 Introduction}

47 Although the standing stock of the autotrophic biomass (phytoplankton) in the ocean is only 48 a small fraction (less than 1\%) of the Earth's photosynthetic biomass, approximately half 49 ( $\sim 50$ gigatonnes $\mathrm{C}$ ) of the global annual carbon-fixation is accounted for by the oceanic au-

${ }_{52}$ tant to be able to make accurate measurements of the standing stocks of phytoplankton 53 tively, on individual pixels. The regional uncertainties in the estimates of phytoplankton carbon are calculated to be less than the relative uncertainties in other satellite-derived products, for most parts of the global ocean, and can amplify only for certain oceanographic regions. Although the new estimates of phytoplankton are of the same order of magnitude as those based on existing models, our study suggests that a consensus is yet to be built on the accurate sizes of the phytoplankton carbon pools; improved satellite chlorophyll products, and better estimates of inherent optical properties would be essential pre-requisites to minimising the uncertainties. 
nity composition; for example, the carbon content of a phytoplankton cell varies with species and its morphological characteristics (e.g., large vs small cell size); it also depends on the ambient light and nutrient conditions (Marañón, 2008; Marañón et al., 2013; Menden-Deuer and Lessard, 2000). Another level of complexity in estimating phytoplankton carbon accurately arises from uncertainties in parameterising the carbon-to-chlorophyll ratio $(\chi)$, which is used to convert phytoplankton-carbon biomass to chlorophyll biomass in ecosystem models for comparison with satellite-derived chlorophyll data, and also in satellite algorithms for estimating phytoplankton carbon from chlorophyll data (Sathyendranath et al., 2009). A standard product from ocean-colour remote sensing is chlorophyll concentration (e.g., http://oceandata.sci.gsfc.nasa.gov/; https://www.oceancolour.org/). Marine biogeochemical and ecosystem models (e.g., http://pft.ees.hokudai.ac.jp/maremip/index.shtml), on the other hand, deal with phytoplankton biomass in carbon units and use a carbon-to-chlorophyll ratio. The magnitude of carbon-to-chlorophyll ratio can vary over two orders of magnitude depending on phytoplankton community composition and environmental conditions (Geider, 1987; Geider et al., 1998; Sathyendranath et al., 2009), and hence it may lead to significant uncertainties in the conversions between the two measures. Furthermore, the retrieval of phytoplankton carbon from remote sensing of ocean colour is also affected by the presence of particulates, other than phytoplankton that contribute to the water-leaving radiance captured by the sensors. Dissolved constituents such as coloured dissolved organic materials (CDOM) that absorbs strongly in the blue wavelengths can also affect the remotely-sensed ocean colour and interfere with chlorophyll-a retrievals, particularly in coastal and high latitudes. Owing to these complexities, the estimation of phytoplankton carbon from remote sensing is recog- 
76

nised as a non-trivial task, and it is essential to improve satellite-based algorithms for use in carbon-cycle research (Behrenfeld et al., 2005; Kostadinov et al., 2016; Sathyendranath et al., 2009).

Nevertheless, algorithms have been developed to compute particulate organic carbon (POC) in the ocean from remotely-sensed ocean colour. For example, Stramski et al. (2008) derived a band-ratio algorithm that uses the blue-to-green band ratio of remote-sensing reflectance to calculate the concentration of POC. This algorithm can then be used to compute phytoplankton carbon by assuming a constant ratio of phytoplankton carbon to POC in the ocean (Stramski et al., 2008). Behrenfeld et al. (2005) derived an empirical relationship to compute phytoplankton carbon from particulate backscattering coefficients by assuming a fixed ratio of $30 \%$ between phytoplankton carbon and POC. More recently, Kostadinov et al. (2016) developed an algorithm to compute phytoplankton carbon from particulate backscattering coefficient using allometric relationships for the POC particle size distribution and assuming that the fraction of carbon in the living phytoplankton relative to that of POC is 1/3. Kostadinov et al. (2016) also computed the absolute and the fractional carbon biomass in three size classes of phytoplankton, i.e., picoplankton (with diameter 0.5-2 $\mu \mathrm{m}$ ), nanoplankton (with diameter 2-20 $\mu \mathrm{m}$ ) and microplankton (with diameter 20-50 $\mu \mathrm{m}$ ), under these assumptions. Although the existing algorithms may provide a mutually comparable estimate (in order of magnitude) of total phytoplankton carbon in the global ocean, the underlying assumption of a constant ratio of phytoplankton carbon and POC imposes significant uncertainties in regional estimates of phytoplankton carbon and its spatial distributions. This 
97

from $14 \%$ to $85 \%$, across a variety of oceanographic regions (Behrenfeld et al., 2005; DuRand

et al., 2001; Eppley et al., 1992; Gundersen et al., 2001; Kostadinov et al., 2016; Oubelkheir et al., 2005; Redalje and Laws, 1981; Stramski et al., 2008). Furthermore, with the exception of Kostadinov et al. (2016), current algorithms are limited in their ability to retrieve the carbon-based classification of phytoplankton functional types (PFT) or phytoplankton size classes (PSC), though many methods are available to estimate the fractional chlorophyll distribution across PFTs and PSCs (e.g., IOCCG, 2014). Given the importance and wide applications of satellite-based PFTs, it is important to improve our understanding on phytoplankton carbon stocks in various PSCs and PFTs, through developing new algorithms based on complementary bio-optical variables.

In this paper, we present a new bio-optical algorithm to estimate phytoplankton carbon from remotely-sensed ocean-colour data, designed by targeting the photosynthetic phytoplankton cells directly. The algorithm builds on Roy et al. (2013), where we developed a semi-analytical method to compute the exponent of the phytoplankton size spectrum from the specific-absorption coefficient of phytoplankton (which depends on chlorophyll concentration and total absorption by phytoplankton), and derived the equivalent spherical diameter of phytoplankton cells and the fractions of chlorophyll in any size class of phytoplankton, in particular, those for picoplankton, nanoplankton and microplankton. Here, the method is extended for computing carbon-to-chlorophyll ratio from ocean colour applicable to any 7 size class of phytoplankton, by combining analytically the allometric relationships between 
118

119

120

121

122

123

124

125

126

127

128

129

130

131

132

133

134

135

136

137

phytoplankton cell size and carbon content with the size-spectrum algorithm of Roy et al. (2013, 2011), and implementing them to estimate phytoplankton carbon in any size class.

The method is applied to ocean-colour data for the period 1997-2013, and is validated using the available in situ data. Results are discussed in relation to the applicability of this method to obtain independent remote-sensing-based measurements of phytoplankton carbon, and the carbon budget, according to phytoplankton size. The results pave the way to improved implementation of carbon-based growth models using satellite data for computation of primary production in various PSCs.

\section{Data}

We used a continuous time series of ocean-colour data on global scale produced by the European Space Agency's Ocean Colour Climate Change Initiative (OC-CCI) project (http://www.esa-oceancolour-cci.org) through systematically merging the available satellite data from three major sensors: NASA-SeaWiFS, NASA-MODIS-Aqua and ESA-MERIS. For temporal consistency of OC-CCI products, and for algorithms selected for processing them, please see Belo Couto et al. (2016); Brewin et al. (2015); Müller et al. (2015). We used the global 4-km, level-3 mapped products from OC-CCI, the details of which can be found in http://www.esa-oceancolour-cci.org (also in, Sathyendranath et al., unpublished ms). Further, to validate the new algorithm we used a global dataset on pico-phytoplankton carbon compiled by Buitenhuis et al. (2012) that included flow cytometry data obtained since the late 1980s during cruises throughout most of the world ocean, as a contribution to the MARE- 
DAT World Ocean Atlas of Plankton Functional Types database. The details of the database can be found in Buitenhuis et al. (2012) and in http://doi.pangaea.de/10.1594/PANGAEA.

We extracted a subset of this database to cover the time period from September 1997 to December 2013, over which the satellite-based ocean-colour data were available. We further obtained mixed-layer depths from Monthly Isopycnal \& Mixed-layer Ocean Climatology (MIMOC, Schmidtko et al., 2013, http://www.pmel.noaa.gov/mimoc/), and remapped those to OC-CCI 4-km grids using nearest-neighbour interpolation (using MATLAB2015b interpolation routine).

\section{Development of the bio-optical algorithm}

\subsection{Exponent of phytoplankton size spectra $(\xi)$ from their absorp- tion coefficients $a_{p h}(\lambda)$ following Roy et al. (2013)}

The exponent of the phytoplankton size spectrum $(\xi)$ can be computed from the absorption coefficient of phytoplankton at $676 \mathrm{~nm}, a_{p h}(676)$, using a method developed by Roy et al. (2013). For the completeness of the methodology of this paper, we briefly describe below the principal steps for retrieval of $\xi$, without fully reproducing it from Roy et al. (2013). In this method, it was assumed that the particle size distribution of phytoplankton cells follows the power law, so the number of phytoplankton cells per unit volume of seawater with a particle diameter of $D$ was expressed as $N(D)=k D^{-\xi}$, with $\xi$ as the exponent of the phytoplankton size spectrum, and $k$ a constant related to the abundance of the total population. A 
157

relationship was then derived between the concentration of chlorophyll-a ( $B$ in $\mathrm{mg} \mathrm{Chl} \mathrm{m}^{-3}$ ) within a diameter range $\left[D_{\min }, D_{\max }\right]$ of phytoplankton cells and the exponent of the phytoplankton size spectrum, by considering that the concentration of chlorophyll-a within the size interval (diameter range $\left.\left[D_{\min }, D_{\max }\right]\right)$ would be a product of the number of phytoplankton cells within that size class, the volume of each cell, and the intracellular concentration of chlorophyll-a $\left(c_{i}\right)$. The quantity $c_{i}\left(\mathrm{mg}\right.$ Chl-a $\left.\mathrm{m}^{-3}\right)$ was parameterised as : $c_{i}=c_{0} D^{-m}$, with the parameters $c_{0}=3.9 \times 10^{6}\left(\mathrm{mg}\right.$ Chl-a $\left.\mathrm{m}^{-2.94}\right)$ and $m=0.06$ (dimensionless), which were estimated earlier by Roy et al. (2011) using the in situ measurements published by Maranón et al. (2007). The concentration of chlorophyll-a ( $B$ in $\mathrm{mg} \mathrm{Chl}^{-3}$ ) within the set diameter range was then expressed as a function of $\xi$ as follows:

$$
B=\int_{D_{\min }}^{D_{\max }}\left[\left(\frac{\pi}{6} D^{3}\right)\left(c_{0} D^{-m}\right)\left(k D^{-\xi}\right)\right] d D=\left(\frac{\pi}{6} k c_{0}\right) \frac{D_{m a x}^{4-\xi-m}-D_{\min }^{4-\xi-m}}{4-\xi-m}
$$

with the parameters $k, c_{o}$ and $m$ described as above.

Next, the specific absorption coefficient of chlorophyll-a $\left(a_{c h l}^{*}\right.$, as distinct from the specific absorption of phytoplankton $a_{p h}^{*}$ ) was expressed as a function of the cell diameter $(D)$. To do so, phytoplankton absorption coefficient $\left(a_{p h}\right)$ at $676 \mathrm{~nm}$ was considered with the assumption that at this wavelength the contribution from auxiliary pigments, and substances other than chlorophyll-a would be negligible (Roy et al., 2011). At this wavelength, the specific absorption coefficient of the cell material of phytoplankton was assumed to be equal to $a_{c i}^{*}$, the specificabsorption coefficient of chlorophyll-a inside the cell, with units of $\mathrm{m}^{2}$ (mg Chl-a) ${ }^{-1}$ (Roy et al., 2011); and following Duyens (1956), the theoretical value of the chlorophyll-specific absorption of phytoplankton cells of diameter $D$ was expressed as: $a_{c h l}^{*}(676, D)=\left[3 a_{c i}^{*} Q_{a}\left(\rho_{c}\right)\right] / 2 \rho_{c}$, with 
177

178

179

180

181

183

184

$Q_{a}$ as the dimensionless absorption efficiency of a cell given by $Q_{a}\left(\rho_{c}\right)=1+\left[2 \exp \left(-\rho_{c}\right)\right] / \rho_{c}+$ $2\left[\exp \left(-\rho_{c}\right)-1\right] / \rho_{c}^{2}$, and $\rho_{c}$ as the dimensionless optical thickness of the cell given by $\rho_{c}=$ $\rho_{c}(676, D)=a_{c i}^{*}(676) c_{0} D^{1-m}$. The observed absorption coefficient of chlorophyll-a at $676 \mathrm{~nm}$ due to the phytoplankton cells in the prescribed diameter range was then expressed as:

$$
a_{c h l}(676)=\int_{D_{\min }}^{D_{\max }}\left[\left(\frac{\pi}{6} D^{3}\right)\left(c_{0} D^{-m}\right)\left(k D^{-\xi}\right) \times a_{c h l}^{*}(676, D)\right] d D
$$

Using Eqs. (1) and (2), the specific absorption of chlorophyll-a at $676 \mathrm{~nm}$, due to phytoplankton cells in the diameter range $\left[D_{\min }, D_{\max }\right]$, was obtained as:

$$
\begin{aligned}
a_{c h l}^{*}(676) & =\frac{a_{c h l}(676)}{B}=\frac{1}{B} \int_{D_{\min }}^{D_{\max }}\left[\left(\frac{\pi}{6} D^{3}\right)\left(c_{0} D^{-m}\right)\left(k D^{-\xi}\right) a_{c h l}^{*}(676, D)\right] d D \\
& =\frac{4-\xi-m}{D_{\max }^{4-\xi-m}-D_{\min }^{4-\xi-m}} \int_{D_{\min }}^{D_{\max }}\left[D^{3-\xi-m} \times a_{c h l}^{*}(676, D)\right] d D .
\end{aligned}
$$

3 Note that, $a_{c h l}^{*}(676, D)$ on the right-hand side of the above equation is the theoretical value of the specific-absorption coefficient of chlorophyll-a at $676 \mathrm{~nm}$, expressed as a function of the equivalent spherical diameter $D$ of phytoplankton, as described above based on Roy et al. (2011). For remote-sensing applications, $a_{p h}^{*}(676)$ is obtained from ocean colour by an algorithm for inherent-optical properties (IOP), for example, the Carder et al. (1999) algorithm as implemented in Roy et al. (2013). Further, from $a_{p h}^{*}(676)$, the quantity $a_{c h l}^{*}(676)$ is calculated using the method of Roy et al. (2011). The quantity $\xi$ is then estimated from Eq. (3) numerically, by using a non-linear optimization algorithm. For further details on the methodology, parameterisation and optimization algorithm associated with the retrieval of $\xi$, 2 the reader is referred to Roy et al. $(2013,2011)$. 


\subsection{Relating $\xi$ to phytoplankton carbon and carbon-to-chlorophyll} ratio $(\chi)$ using allometric relationships

Allometric relationships appear to hold for phytoplankton communities, as well as for other organisms (Marañón, 2008; Marañón et al., 2013; Menden-Deuer and Lessard, 2000; Peters, 1983; Strathmann, 1967). Menden-Deuer and Lessard (2000) have reported allometric relationships between the cellular content of phytoplankton carbon $\left(C_{\text {cell }}\right)$ and cell volume $\left(V_{\text {cell }}\right)$ for morphologically different dinoflagellates, diatoms and other protist groups. The allometric relationships take the following canonical form:

$$
C_{\text {cell }}=a V_{\text {cell }}^{b}
$$

where $V_{\text {cell }}$ is the volume of a phytoplankton cell expressed in $\mu \mathrm{m}^{3}, C_{\text {cell }}$ is expressed in pg Cell ${ }^{-1}$, and the quantities $a$ and $b$ are constants, which should ideally remain unchanged for a given ecological community. The concentration of phytoplankton carbon $\left(C_{\text {total }}\right.$, in $\mathrm{mgC} \mathrm{m}^{-3}$ ) contained in the cells within a diameter range $\left[D_{\min }, D_{\max }\right]$ can then be expressed as:

$$
\begin{aligned}
C_{\text {total }} & =\int_{D_{\min }}^{D_{\max }}[\text { number of cells }] \times[\text { carbon content within a cell }] d D, \\
& =\int_{D_{\min }}^{D_{\max }}\left(k D^{-\xi}\right)\left[10^{-9} a\left(10^{18} \frac{\pi}{6} D^{3}\right)^{b}\right] d D \\
& =10^{-9} k a\left(10^{18} \frac{\pi}{6}\right)^{b}\left(\frac{D_{\max }^{3 b-\xi+1}-D_{\min }^{3 b-\xi+1}}{3 b-\xi+1}\right) .
\end{aligned}
$$

We note that the values $10^{-9}$ and $10^{18}$ are associated with the conversions of units from picogram to $\mathrm{mg}$, and $\mathrm{m}^{3}$ to $\mu \mathrm{m}^{3}$, respectively. In the special case when $\xi \rightarrow(3 b+1)$, the denominator in Eq. (5) goes to zero; so, to avoid division by zero, a limit of $C_{\text {total }} \rightarrow$ 
${ }_{209}\left[10^{-9} k a\left(10^{18} \frac{\pi}{6}\right)^{b} \log _{e}\left(\frac{D_{\max }}{D_{\min }}\right)\right]$, is used. Equations (1) and (5) relate $\xi$ to the concentration ${ }_{210}$ of total phytoplankton chlorophyll $\left(B, \mathrm{mg} \mathrm{m}^{-3}\right)$ and the total phytoplankton carbon $\left(C_{\text {total }}\right.$, $\left.{ }_{211} \mathrm{mg} \mathrm{m}^{-3}\right)$, respectively, from which the carbon-to-chlorophyll ratio $(\chi)$ of the mixed population 212 can be calculated as

$$
\chi=\frac{C_{t o t a l}}{B}=\frac{10^{-9} a\left(10^{18} \pi / 6\right)^{b}}{(\pi / 6) c_{0}}\left(\frac{D_{\max }^{3 b-\xi+1}-D_{\min }^{3 b-\xi+1}}{D_{\max }^{4-\xi-m}-D_{\min }^{4-\xi-m}}\right)\left(\frac{4-\xi-m}{3 b-\xi+1}\right) .
$$

${ }_{213}$ We note that the only unknown parameter $k$ appearing in both Eqs. (1) and (5) cancels out 214 within the expression of carbon-to-chlorophyll ratio (6). Once the exponent $\xi$ is computed ${ }_{215}$ from Eq. (3) following the description in the previous section, $\chi$ can be computed directly ${ }_{216}$ from Eq. (6). Therefore, the total phytoplankton carbon can be calculated simply as,

$$
C_{\text {total }}=\chi B=\frac{10^{-9} a\left(10^{18} \pi / 6\right)^{b}}{(\pi / 6) c_{0}}\left(\frac{D_{\max }^{3 b-\xi+1}-D_{\min }^{3 b-\xi+1}}{D_{\max }^{4-\xi-m}-D_{\min }^{4-\xi-m}}\right)\left(\frac{4-\xi-m}{3 b-\xi+1}\right) B .
$$

${ }_{217}$ It is clear that the estimates of phytoplankton carbon, using the above equations for $\chi$ 218 and $C_{\text {total }}$, would depend on accurate parameterisation of the allometric relationship between ${ }_{219}$ phytoplankton cell volume and cellular carbon. However, the allometric parameters $a$ and $b$ 220 are reported to vary across phytoplankton groups (Menden-Deuer and Lessard, 2000). So, 221 the estimates of mixed phytoplankton carbon would be biased if the allometric parameters 222 corresponding to any one phytoplankton group were used (Fig. 1a). More explicitly, according 223 to Menden-Deuer and Lessard (2000), if the allometric relationship for protists (green line 224 in Fig. 1a) were used, phytoplankton carbon would be underestimated for small cells and 225 overestimated for large cells; if that for diatoms (blue line in Fig. 1a) were used, phytoplankton 226 carbon would be underestimated for large cells; and finally, if that for dinoflagellate (yellow 227 line in Fig. 1a) were used, phytoplankton carbon would be overestimated for small cells. 

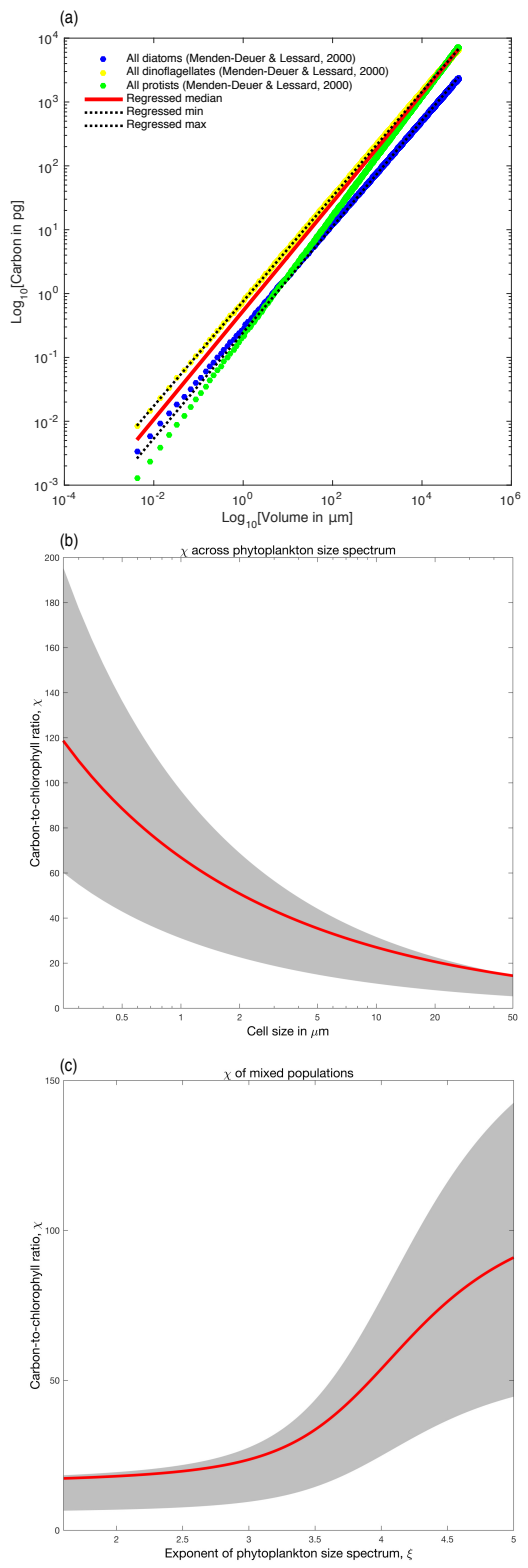

Figure 1: Reported and derived allometric relationships between phytoplankton carbon and their cell size. (a) Allometric carbon of diatoms (blue), dinoflagellates (yellow) and protists (green) reported by Menden-Deuer and Lessard (2000); and the allometric carbon for mixed phytoplankton a function of their cell volume derived by regression; the regressed median $(a=0.54, b=0.85)$, and the lower $(a=0.25, b=0.83)$ and upper $(a=0.76, b=0.82)$ bounds are shown by red solid line, and two black-dotted lines respectively. (b)-(c) Derived relationship between carbon-to-chlorophyll ratio $\chi$ and phytoplankton size: (b) $\chi$ as a function of phytoplankton cell diameter for a homogenous population, calculated from Eq. (6) and the relationship between $\xi$ to average cell diameter derived in Roy et al. (2013); and (c) $\chi$ as a function of the exponent of phytoplankton size spectrum $\xi$ calculated from Eq. (6). In (b) and (c), the red lines represent the median of the allometric relationship shown in (a); and the grey areas represent the ranges of $\chi$ corresponding to the regressed minimum and maximum shown as black-dotted lines in (a). 
Therefore, for calculating cellular carbon of mixed phytoplankton operationally, the allometric parameters need to be established, which is not straight-forward. In a recent study, Kostadinov et al. (2016) considered an approach in which four different allometric relationships reported by Menden-Deuer and Lessard (2000) were used for two different parts of the phytoplankton size spectrum. However, the allometric relationship is scale-free (as known from allometric studies based on other species, e.g., Peters, 1983), and therefore, the allometric parameters should remain unchanged across the size range of the phytoplankton community. But deriving a new allometric relationship for phytoplankton based on in situ data, applicable to all oceanographic regions and across all size ranges of mixed phytoplankton, is out of the scope of this study, which aims at making a first estimate of phytoplankton carbon using reported allometric relationships, and the new method. So, from an operational perspective, we considered the various estimates of ' $a$ ' and ' $b$ ' reported by Menden-Deuer and Lessard (2000) as independent observations, and derived, as described below, a continuous allometric relationship with a view to applying them to mixed populations, assuming that the populations are combinations of the phytoplankton groups for which the allometric relationships were reported by Menden-Deuer and Lessard (2000). In this approach, we first computed phytoplankton carbon over a broad range of cell volumes using the allometric relationships reported for protists, diatoms and dinoflagelletes, respectively (shown by the green, blue and yellow dots, respectively in Fig. 1a). We next computed the median, minimum and maximum of the three estimates of phytoplankton carbon, at each size, over the same range of cell volumes (see, Fig. 1a). We then derived three allometric relationships between cell volume and the median, minimum and maximum estimates of phytoplankton carbon, respec- 
tively, using linear regression (the median is shown by solid red line, and the minimum and maximum by dotted back lines in Fig. 1a). As expected, the revised allometric parameters, corresponding to the regressed median $\left(a=0.54, b=0.85, r^{2}>0.95\right)$, minimum $(a=0.25$, $\left.b=0.83, r^{2}>0.95\right)$ and maximum $\left(a=0.76, b=0.82, r^{2}>0.95\right)$, differed from the reported allometric parameters corresponding to any particular phytoplankton group. However, the regressed median line (red) in Fig. 1a would represent an approximate allometric relationship for which the estimates of mixed-phytoplankton carbon would always be within the range of estimates based on single phytoplankton groups. Furthermore, the minimum and maximum estimates of the phytoplankton carbon at any size would be represented by the lower and upper bounds for the allometric relationships (the dotted black lines in Fig. 1a) derived this way from the group-specific allometric relationships.

The allometric parameters ' $a$ ' and ' $b$ ', derived by regression as above, can be incorporated into the expression for carbon-to-chlorophyll ratio $\chi$ (Eq. 6) to describe the variations of $\chi$ with phytoplankton size structure. For phytoplankton populations consisting of homogeneous cells of the same size, the variation of $\chi$ as a function of the cell size of the population is shown in Fig. (1b). When the population deviates from homogeneity and consists of cells of different sizes, $\chi$ varies as a function of the exponent of size spectrum according to Fig. (1c). The magnitude of $\chi$ decreases with increase in cell size (Fig. (1b, the black curve). For mixed populations, $\chi$ increases with the exponent of phytoplankton size spectrum $\xi$ (Fig. (1c, the black curve). The shaded areas in Fig. (1b) and Fig. (1c) represent the lower and upper levels of $\chi$ corresponding to the regressed-minimum and maximum of the allometric relationship. 
271

272

273

274

275

276

277

278

279

280

281

282

283

284

285

286

287

288

The figures (1b-1c) show that the carbon-to-chlorophyll ratio of phytoplankton will be at the higher end (e.g., $\chi>100$ ) when the population is dominated by small cells, and would decrease to a significantly lower value (e.g., $\chi<20)$ if the population were dominated by large cells. These results are remarkably consistent, qualitatively, with empirically derived carbonto-chlorophyll ratios, e.g., those in Sathyendranath et al. (2009).

We next apply these relationships to derive analytical expressions for $\chi$ and phytoplankton carbon for any given size class of phytoplankton population. Although we have used the above allometric parameters for the rest of the calculations to obtain a first estimate of phytoplankton carbon by our method, any improvement on the allometric relationships based on new in situ data would improve our estimates of phytoplankton carbon, and it would be straight-forward to incorporate any new parameter estimates into our method.

\subsection{Carbon-to-chlorophyll ratio $(\chi)$ and fractions of carbon for any size class of phytoplankton}

Considering that the biomass of phytoplankton (in carbon units) is the sum of biomasses in $n$ non-overlapping size classes, the carbon biomass $C_{i j}$ of a size class defined by the size (diameter) range $\left[D_{i}, D_{j}\right]$ with $0 \leq i<j \leq n$, can be expressed as the product of the carbon-to-chlorophyll ratio $\chi_{i j}$ and the chlorophyll concentration $B_{i j}$ of that size class. Using

Eq. (6) and the expression for $B_{i j}$ from Roy et al. (2013), the carbon content of any size class 
289

$C_{i j}$ can be expressed as,

$$
C_{i j}=\chi_{i j} B_{i j}=\chi_{i j}\left(\frac{D_{j}^{4-\xi-m}-D_{i}^{4-\xi-m}}{D_{m a x}^{4-\xi-m}-D_{\min }^{4-\xi-m}}\right) B
$$

290

The total phytoplankton carbon can then be expressed as a sum of phytoplankton carbon 291 from $n$ size classes,

$$
C_{\text {total }}=\sum_{i=0, j=i+1}^{i=n-1, j=n} C_{i j}=\frac{B}{D_{\max }^{4-\xi-m}-D_{\min }^{4-\xi-m}} \sum_{i=0, j=i+1}^{i=n-1, j=n}\left[\chi_{i j}\left(D_{j}^{4-\xi-m}-D_{i}^{4-\xi-m}\right)\right],
$$

292

where the carbon-to-chlorophyll ratio $\chi_{i j}$ of the size class $\left[D_{i}, D_{j}\right]$ follows directly from Eq. (6),

$$
\chi_{i j}=\frac{10^{-9} a\left(10^{18} \pi / 6\right)^{b}}{(\pi / 6) c_{0}}\left[\frac{D_{j}^{3 b-\xi+1}-D_{i}^{3 b-\xi+1}}{D_{j}^{4-\xi-m}-D_{i}^{4-\xi-m}}\right]\left[\frac{4-\xi-m}{3 b-\xi+1}\right] .
$$

293 294

299

$$
F_{i j}=\frac{C_{i j}}{C_{\text {total }}}=\frac{\chi_{i j}\left(D_{j}^{4-\xi-m}-D_{i}^{4-\xi-m}\right)}{\sum_{i=0, j=i+1}^{i=n-1, j=n}\left[\chi_{i j}\left(D_{j}^{4-\xi-m}-D_{i}^{4-\xi-m}\right)\right]} .
$$

295 In particular, if $\left[D_{0}, D_{1}\right],\left[D_{1}, D_{2}\right]$ and $\left[D_{2}, D_{3}\right]$ represent the ranges of cell diameters corresponding to picoplankton, nanoplankton and microplankton respectively, the carbon-tochlorophyll ratio corresponding to the three size classes $\left(\chi_{p}, \chi_{n}\right.$ and $\left.\chi_{m}\right)$ can be respectively computed using Eq. (10) as follows:

$$
\chi_{p}=\frac{10^{-9} a\left(10^{18} \pi / 6\right)^{b}}{(\pi / 6) c_{0}}\left[\frac{D_{1}^{3 b-\xi+1}-D_{0}^{3 b-\xi+1}}{D_{1}^{4-\xi-m}-D_{0}^{4-\xi-m}}\right]\left[\frac{4-\xi-m}{3 b-\xi+1}\right]
$$

$$
\chi_{n}=\frac{10^{-9} a\left(10^{18} \pi / 6\right)^{b}}{(\pi / 6) c_{0}}\left[\frac{D_{2}^{3 b-\xi+1}-D_{1}^{3 b-\xi+1}}{D_{2}^{4-\xi-m}-D_{1}^{4-\xi-m}}\right]\left[\frac{4-\xi-m}{3 b-\xi+1}\right] \text {; }
$$

300

$$
\chi_{m}=\frac{10^{-9} a\left(10^{18} \pi / 6\right)^{b}}{(\pi / 6) c_{0}}\left[\frac{D_{3}^{3 b-\xi+1}-D_{2}^{3 b-\xi+1}}{D_{3}^{4-\xi-m}-D_{2}^{4-\xi-m}}\right]\left[\frac{4-\xi-m}{3 b-\xi+1}\right] .
$$


Moreover, using equation (11) and equations (12-14), the fractions of carbon for picoplankton $\left(F_{p}\right)$, nanoplankton $\left(F_{n}\right)$ and microplankton $\left(F_{m}\right)$ can be computed as follows:

$$
\begin{aligned}
& F_{p}=\frac{\chi_{p}\left(D_{1}^{4-\xi-m}-D_{0}^{4-\xi-m}\right)}{\left[\chi_{p}\left(D_{1}^{4-\xi-m}-D_{0}^{4-\xi-m}\right)+\chi_{n}\left(D_{2}^{4-\xi-m}-D_{1}^{4-\xi-m}\right)+\chi_{m}\left(D_{3}^{4-\xi-m}-D_{2}^{4-\xi-m}\right)\right]} \\
& F_{n}=\frac{\chi_{n}\left(D_{2}^{4-\xi-m}-D_{1}^{4-\xi-m}\right)}{\left[\chi_{p}\left(D_{1}^{4-\xi-m}-D_{0}^{4-\xi-m}\right)+\chi_{n}\left(D_{2}^{4-\xi-m}-D_{1}^{4-\xi-m}\right)+\chi_{m}\left(D_{3}^{4-\xi-m}-D_{2}^{4-\xi-m}\right)\right]} \\
& F_{m}=\frac{\chi_{m}\left(D_{3}^{4-\xi-m}-D_{2}^{4-\xi-m}\right)}{\left[\chi_{p}\left(D_{1}^{4-\xi-m}-D_{0}^{4-\xi-m}\right)+\chi_{n}\left(D_{2}^{4-\xi-m}-D_{1}^{4-\xi-m}\right)+\chi_{m}\left(D_{3}^{4-\xi-m}-D_{2}^{4-\xi-m}\right)\right]}
\end{aligned}
$$

Consistent with the previous studies (Roy et al., 2013; Sieburth et al., 1978; Vidussi et al., 2001), the diameter bounds of pico-, nano-, and micro- size classes may be taken as $D_{0}=0.2$ $\mu m, D_{1}=2 \mu m, D_{2}=20 \mu m$, and $D_{3}=50 \mu m$. Applying these limits to Eq. (10), the carbon-to-chlorophyll ratios of picoplankton, nanoplankton, and microplankton can be plotted as functions of the exponent of the phytoplankton size spectrum as in Fig. (2a). Compared with the carbon-to-chlorophyll ratio of the mixed population (black curve, Fig. 2a), carbon-to-chlorophyll ratio of picoplankton (blue curve, Fig. 2a) is always higher, but that of microplankton (red curve, Fig. 2a) is always lower, over the range values of $\xi$. On the other hand, the carbon-to-chlorophyll ratio of the nanoplankton (green curve, Fig. 2a) is less than that of the mixed population for low values of $\xi$, and is greater than that of the mixed population for the high values of $\xi$ (Fig. 2a). The range of variation of carbon-to-chlorophyll ratio is the minimum for micro-size class, and maximum for pico-size group (Fig. 2a).

The proportions of phytoplankton carbon corresponding to the three size classes, when plotted as functions of $\xi$ (the solid blue, green and red lines corresponding to pico-, nanoand micro classes, respectively in Fig. 2b), have shapes similar to those obtained for the 

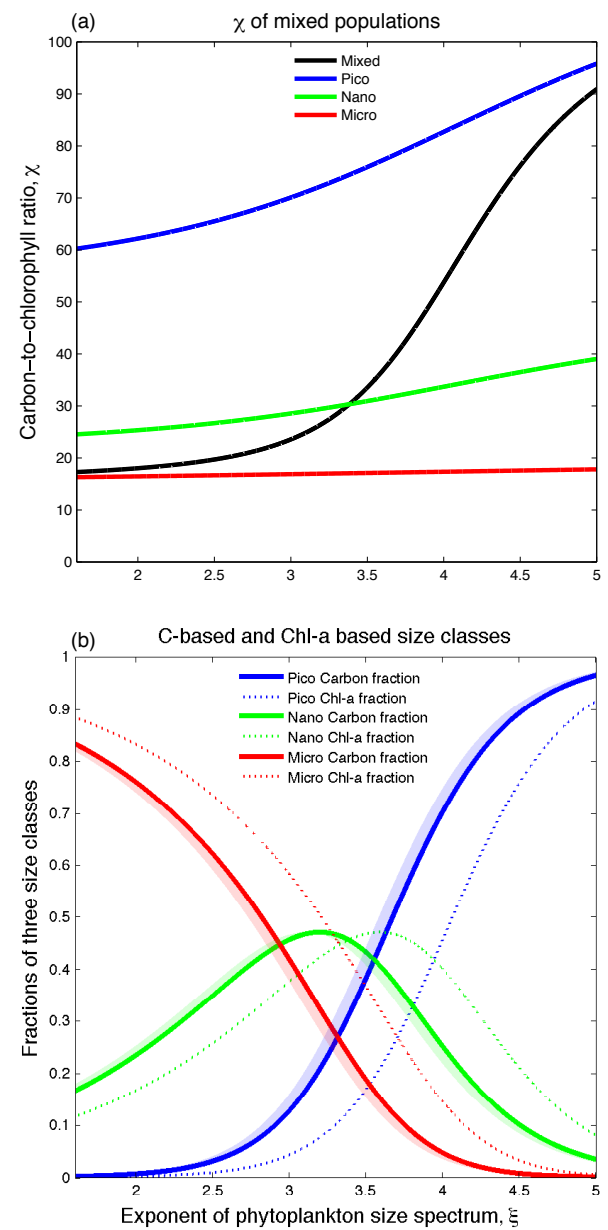

Figure 2: Carbon-to-chlorophyll ratio $\chi$ and phytoplankton carbon derived for various size classes of phytoplankton. (a) $\chi$ of mixed phytoplankton (black line, using Eq. 6), picoplankton (blue line, using Eq. 12), nanoplankton (green line, using Eq. 13) and microplankton (red line, using Eq. 14) plotted as functions of the exponent of phytoplankton size spectrum $\xi$. (b) Size-fractionated phytoplankton carbon and chlorophyll plotted as functions of $\xi$. The solid blue, green and red lines represent the fractions of phytoplankton carbon corresponding to picoplankton (using Eq. 15), nanoplankton (using Eq. 16) and microplankton (using Eq. 17); and the shaded area represents the corresponding ranges of carbon fraction. The dotted blue, green and red lines represent fractions of chlorophyll corresponding to picoplankton, nanoplankton and microplankton, as derived in Roy et al. (2013). 
chlorophyll-proportions (the dotted lines, Fig. 2b, based on Roy et al., 2013). However, over the range of $\xi$ relevant for phytoplankton, the fraction of microplankton based on carbon is lower than that based on chlorophyll (the solid and dotted red lines, Fig. 2b); and the fraction of picoplankton based on carbon is higher than that based on chlorophyll (the solid and dotted blue lines, Fig. 2b). On the other hand, the fraction of nanoplankton based on carbon is higher than that based on chlorophyll for low values of $\xi$, but the relationship is reversed for higher values of $\xi$ (the solid and dotted green lines, Fig. 2b). We also note that the uncertainties in allometric parameters result in relatively low uncertainties in the estimates of carbon-based fractions of pico, nano and micro size classes (the blue, green and red shaded areas associated with the corresponding solid lines in Fig. 2b indicate these uncertainties).

\section{Results and discussion}

\subsection{Algorithm validation using in situ data}

Ideally, it would require a large global dataset of in situ phytoplankton carbon to validate the bio-optical method presented here. However, constraints on the availability of in situ data on phytoplankton carbon limit the possibilities for algorithm validation. Nevertheless, we have attempted a validation exercise using the available flow cytometry data on phytoplankton compiled and reported by Buitenhuis et al. (2012) as contribution to the MAREDAT World Ocean Atlas of Plankton Functional Types database. However, this database reported phytoplankton carbon for the pico-size group only, from 1980 onwards, over the world ocean. 
337 $357 \mathrm{mgC} \mathrm{m}{ }^{-3}$.
Therefore, the validation exercise presented here is limited to in situ data on pico-size class, and the statistics may not apply to phytoplankton carbon in other size classes or to the total phytoplankton carbon, which would be a sum of carbon in all size classes. To maximise the number of data points for validation, we have used the reported pico-carbon data over the entire period of satellite coverage i.e., from September 1997 to December 2013, consistent with the OC-CCI v2 satellite data. Given the short time-scale of phytoplankton turn over, the satellite and in situ match-up would be most optimal on a daily scale. Compared with the weekly or monthly products, the choice of daily products would minimise the possible uncertainties that might arise due to time differences between the in situ and satellite observations. We thus computed pico-plankton carbon using our method on the daily maps, and retrieved the spatially matched-up data points, which provided $\sim 900$ data points for validation of pico-carbon.

The locations of the in situ measurements from the MAREDAT database taken for this study are shown in Fig. (3a), and the validation results are shown in Fig. (3b-d). On a linear scale, the Spearman's correlation $(\rho)$ between the in situ picoplankton carbon and the satellite-derived estimates of pico-carbon $\left(\right.$ in $\mathrm{mgC} \mathrm{m}^{-3}$ ) computed by our method is $0.57, p<$ 0.0001 , where the root-mean squared error (RMSE) of the satellite-based estimates is 36.23 $\mathrm{mgC} \mathrm{m}^{-3}$. The data-density plot shows high density (red colour) of sample points below the 1:1 line (black line in Fig. 3b) suggesting that the satellite-derived picoplankton carbon values are lower than the corresponding in situ estimates, and on a linear scale the bias is -13.53 
(a)

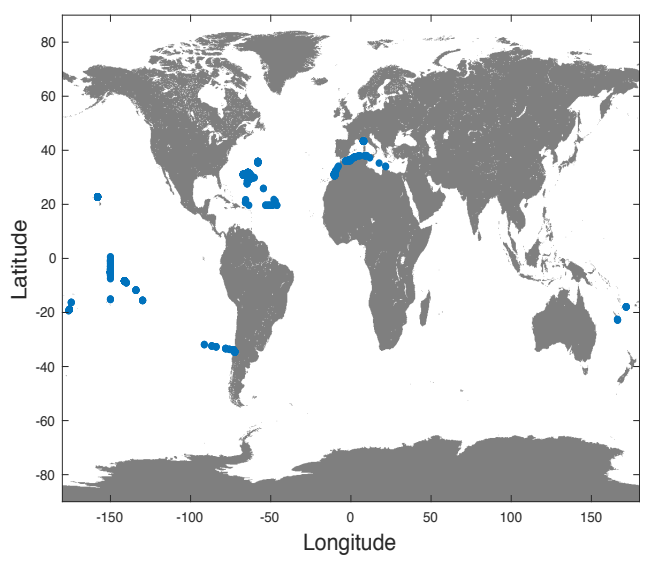

(c)

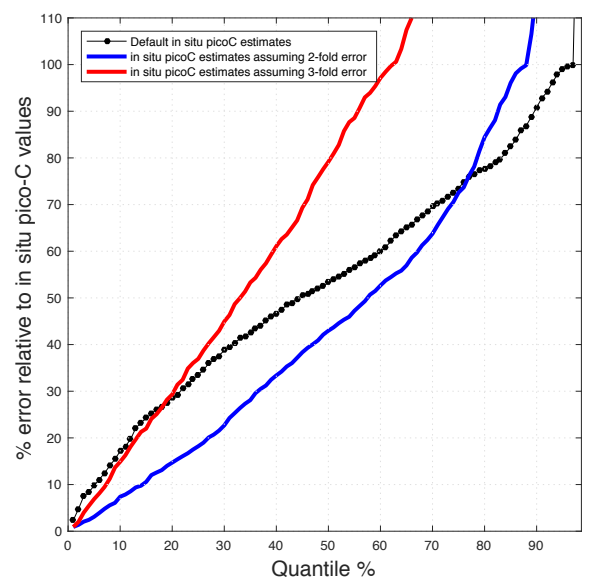

(b)

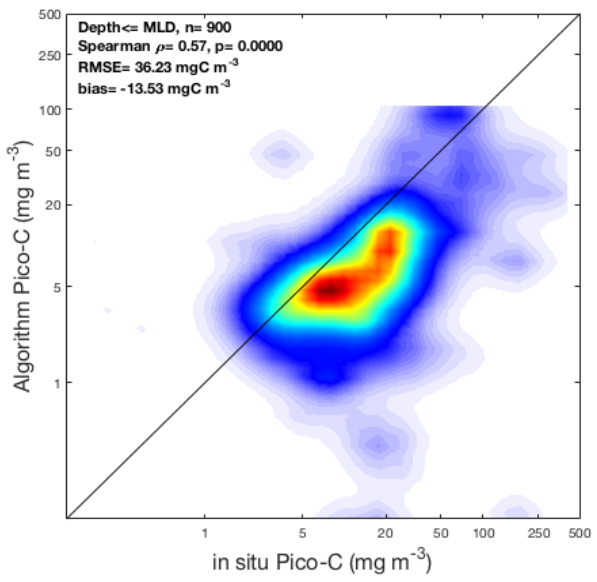

(d)

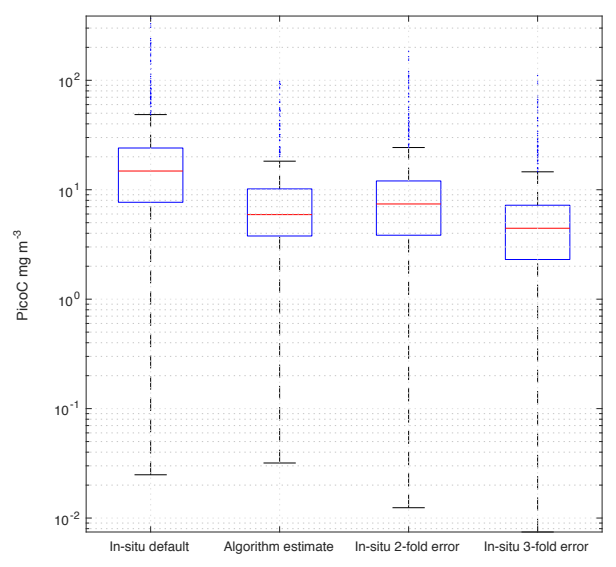

Figure 3: Validation of the computed phytoplankton carbon using in situ data. (a) Locations of the in situ data, which is a part of in situ samples from MAREDAT within the range of satellite coverage, i.e, 1997-2013. The compiled dataset represents in situ measurements of carbon for small-phytoplankton, $<2 \mu \mathrm{m}$ in diameter. Phytoplankton carbon for the corresponding size range was computed using Eq. (8) and Eq. (10). (b) Comparison plot for the observed and computed picoplankton carbon. The increased densities of the data points around the 1:1 line are evident in the high density (red colour) close to the 1:1 line. Lower densities are shown in blue. (c) Magnitudes of the relative error (in \%) in estimation of picocarbon with respect to the reported in situ values presented for data quantiles. The black line indicates the error percentages for the default in situ values, whereas the blue and red lines show those for assumed 2 and 3 fold overestimation in the in situ calculations (these possibilities in MAREDAT are discussed by Buitenhuis et al. (2012)). (d) Box plots of the observed and satellite-derived values of picoplankton carbon corresponding to the default in situ values, and in situ values with possibilities of 2 and 3 fold overestimations. 

377 satellite-derived estimates are $<18 \%$ (or $<35 \%$ ) for a quartile of the data, and $<70 \%$ (or $378>100 \%$ ) for the three quartiles of the data (the blue and red lines, respectively, in 3c). Also, 
379

380

381

382

383

384

385

386

387

388

389

390

391

392

393

394

395

396

397

398

399

the box plots (Fig. 3d) show that the median values and the spread and distributions of the estimated and in situ picoplankton values differ between the default in situ values and the alternative two scenarios: the median value of the estimated pico-carbon is lower than that for the default in situ estimates, but the difference reduces considerably if we take into account the possibilities of a 2-fold or 3-fold overestimation of the in situ pico-carbon, and in fact, corresponding to a 3-fold in situ overestimation, the median of the satellite estimates is higher than those for the in situ estimates (Fig. 3d).

Therefore, our satellite-based estimates show underestimation of picoplankton carbon with respect to the reported in situ estimates, but the level of bias of the current estimates is also subject to the uncertainties in the carbon-per-cell conversion factors applied to the in situ data. The validation might also have been affected by the properties of the statistical distribution of the quantities under comparison; for example, the in situ picoplankton-carbon data were computed in MAREDAT under the assumption of mean cell-to-carbon conversion factors, whereas the algorithm, by design, considered the median of a number of allometric relationships drawn from the literature for different taxa. So, the possibility of non-normality in the in situ picoplankton-carbon distribution would impose a systematic bias, when considering the mean over the median. However, re-calculation of the in situ pico-carbon from MAREDAT database to explore the unknown error characteristics is beyond the scope of our study. The other sources of uncertainties in pico-carbon may also be associated with the uncertainties in the satellite input, e.g., here we have used OC-CCI-version-2 data, which have been re-processed with a view to reducing uncertainties. However, a new version of the data 
400 411 in the gyres to more than $500 \mathrm{mg} \mathrm{m}^{-3}$ in the case-2 and coastal waters (Fig. 4b). The stock 412 413 414 415

(OC-CCI-version-3) has been released only recently, but we are yet to apply our method to the updated version of the data. We further note that the RMSE and bias values presented are based on picoplankton carbon data only, and uncertainties in phytoplankton carbon for other classes would require further investigation.

\section{$4.2 \quad \mathrm{C}: \mathrm{Chl}(\chi)$ and phytoplankton carbon over global ocean}

The average carbon-to-chlorophyll ratios $(\chi)$ computed over the global ocean using composite monthly images from September 1997 to December 2013 vary over a wide range, from <20 in the coastal or case- 2 waters to $>90$ in the open ocean and case- 1 waters (Fig. 4a). These results are consistent with our understanding that the low and high values of $\chi$ represent, respectively, the areas dominated by large and small phytoplankton. The annually-averaged standing stocks of phytoplankton carbon over the mixed layer vary from less than $1 \mathrm{mg} \mathrm{m}^{-3}$ of phytoplankton carbon integrated over the mixed layer and globe is found to be $\sim 0.26$ GtC (Fig. 4b), with some monthly variation in the stock ranging from 0.24 to $0.29 \mathrm{GtC}$. The smallest stock is observed in June with $\sim 0.24 \mathrm{GtC}$ and a maximum in September $\sim 0.29 \mathrm{GtC}$, with the autumn months having stocks of carbon greater than the annual average.

In a recent study, Kostadinov et al. (2016) have shown that the estimates of annual stock of phytoplankton carbon depend on the estimation method, and can vary from 0.2 to 0.32 GtC, with the minimum due to Stramski et al. (2008): $\sim 0.2$ GtC, followed by the average of some CMIP5 models (Taylor et al., 2012): 0.22 GtC, Kostadinov et al. (2016): $\sim 0.24$ 

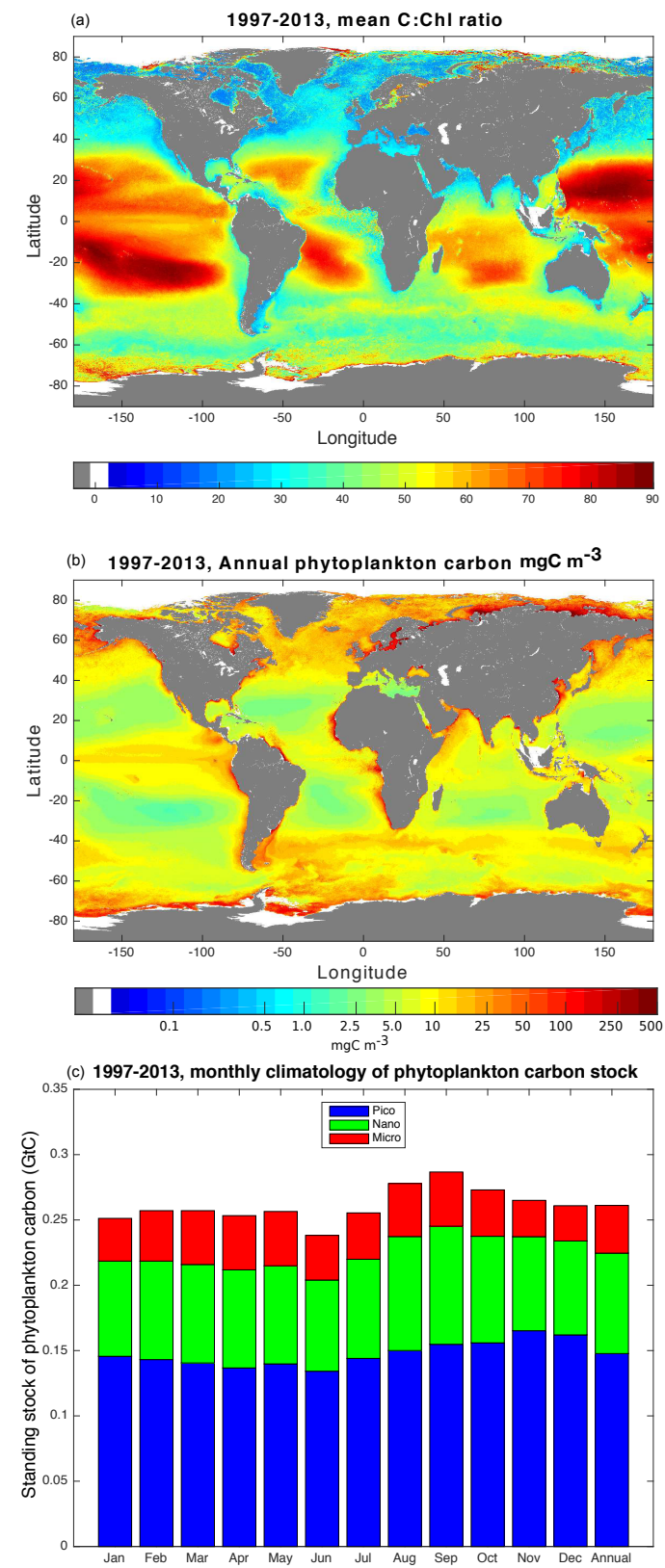

Figure 4: Global distribution of C:Chl and phytoplankton carbon estimated over 1997-2013 using monthly OC-CCI data. (a) Annual climatology of C:Chl over 1997-2013. (b) Annual climatology of phytoplankton carbon in the surface over 1997-2013. (c) Monthly climatology of the global estimates of phytoplankton carbon (in gigaton, GtC) integrated over the mixedlayer depth. Blue, green and red colours indicate the proportions of phytoplankton carbon corresponding to pico-, nano- and micro- size groups. 
420

421

422

423

424

425

426

427

428

429

430

431

432

433

434

435

436

437

438

439

GtC (with a range of 0.2 to $0.3 \mathrm{GtC}$ ) and Behrenfeld et al. (2005): $~ 0.32$ GtC. Our estimate of $\sim 0.26 \mathrm{GtC}$ (with a range of monthly variations between 0.24 and $0.29 \mathrm{GtC}$ ) is slightly

higher than those of Stramski et al. (2008), the average result for CMIP5 models reported by

Kostadinov et al. (2016), and the back-scattering-based method of Kostadinov et al. (2016), but is lower than that reported by Behrenfeld et al. (2005).

\subsection{Size-partitioned phytoplankton carbon over the global ocean}

Using the equations derived in Section 3.3, phytoplankton carbon can be partitioned into any number of size classes, and in particular, into the three broad size classes, e.g., pico, nano, and micro. The annual average of phytoplankton carbon in the three size classes expressed both as the percentages of total phytoplankton and in the units of $\mathrm{mgC} \mathrm{m}^{-3}$ are shown in Fig. (5).

The global distributions of the carbon-based phytoplankton size classes (i.e., the percentages of carbon in three size classes in Fig. 5a-c), are generally similar to the corresponding chlorophyll-based distributions reported in Roy et al. (2013). Pico-carbon stocks generally dominate over those of nano- and micro-carbon for most of the open oceans, including the gyres and the equatorial regions, with contributions ranging from $\sim 70 \%$ to more than $90 \%$ of total phytoplankton carbon (Fig. 5a). Converting the percentages into units of carbon, the concentration of picoplankton carbon in these areas is generally within the range of 1-10 $\mathrm{mgC} \mathrm{m}{ }^{-3}$ (Fig. 5d). In most of the coastal waters and generally in the northern hemisphere, the pico-carbon stocks are around 10-20\% of the total phytoplankton carbon (Fig. 5a); how- 

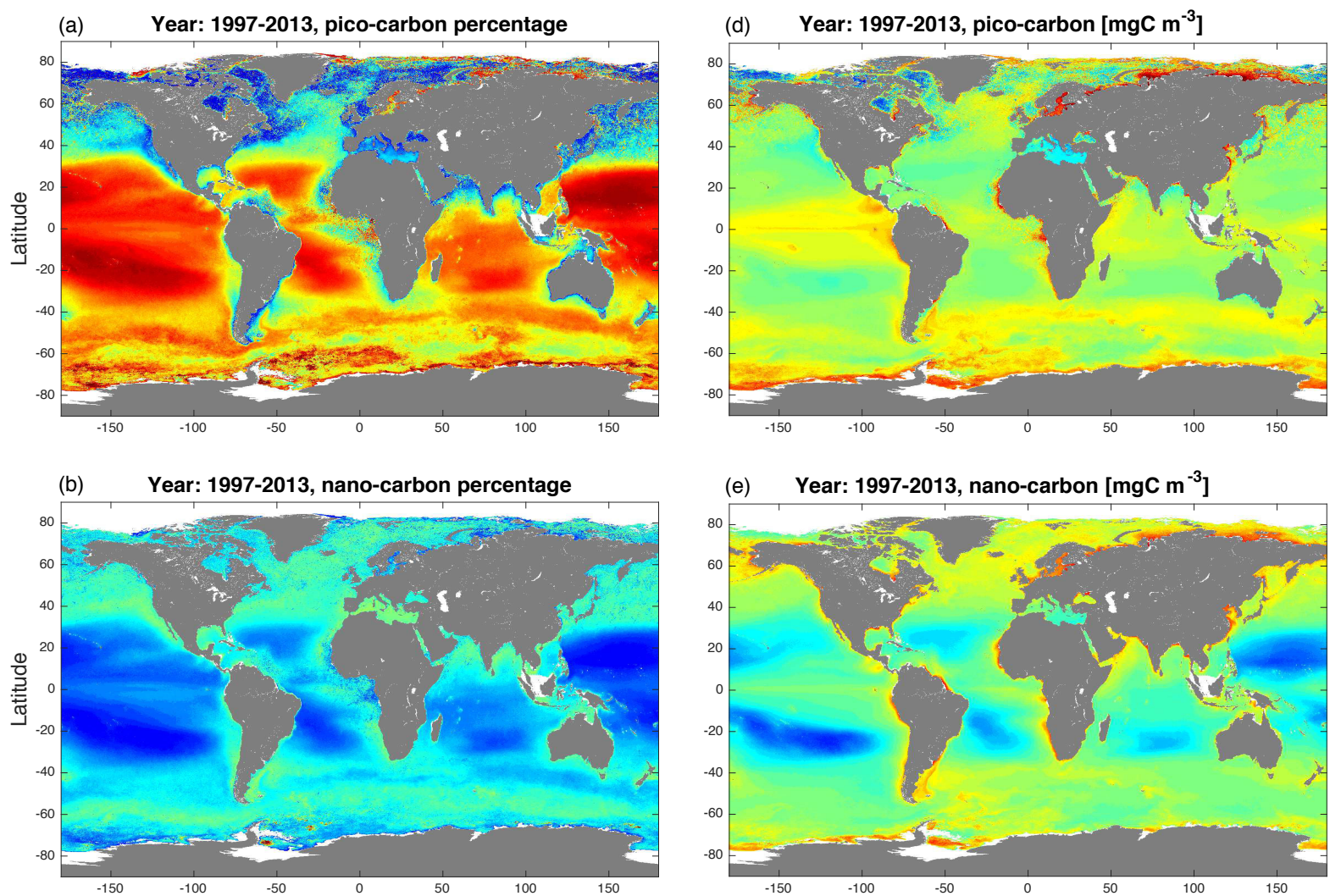

(e) Year: 1997-2013, nano-carbon $\left[\mathrm{mgC} \mathrm{m}^{-3}\right.$ ]
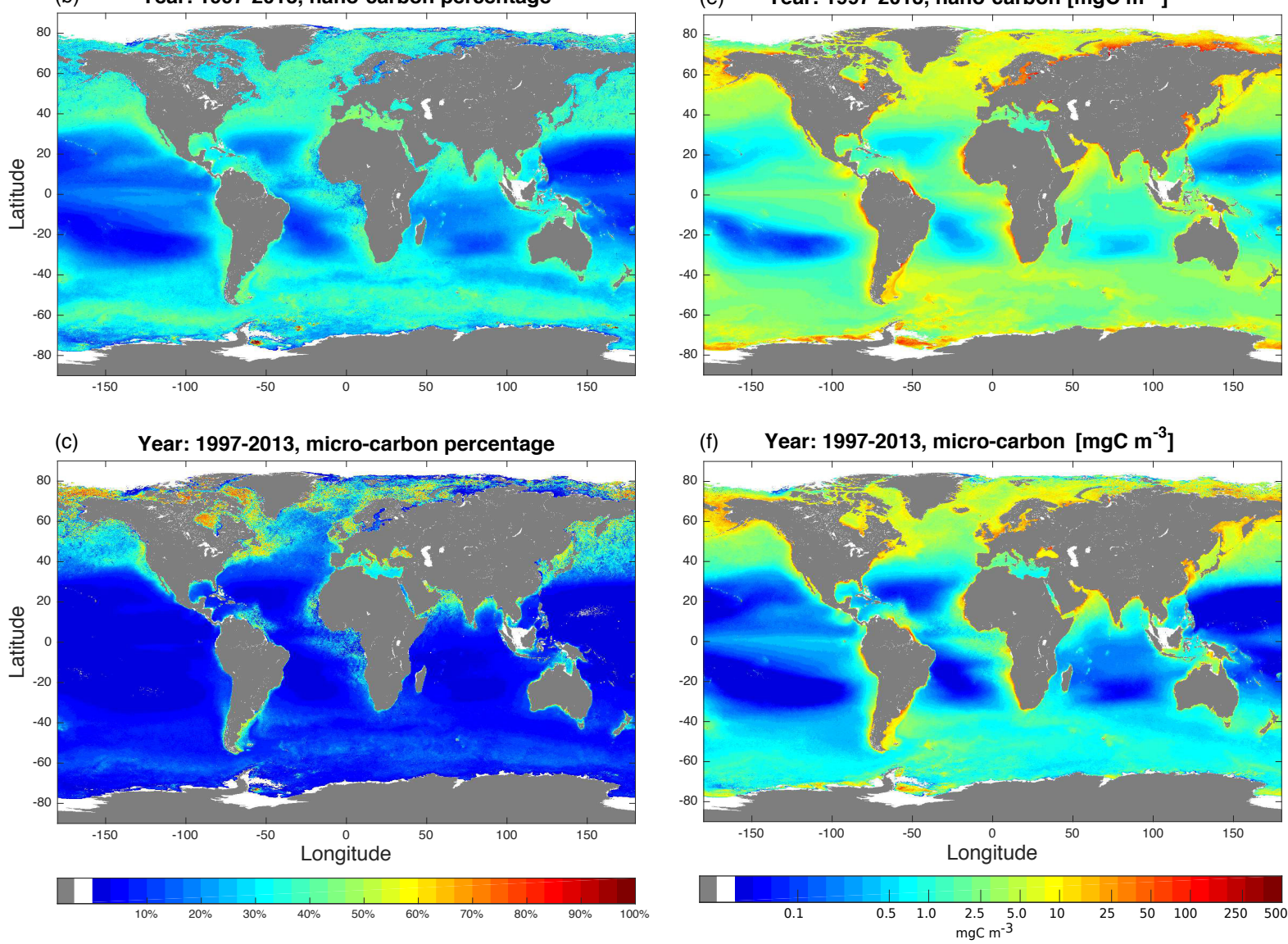

Figure 5: Global average distribution of phytoplankton carbon corresponding to pico-, nanoand micro- size groups estimated by averaging monthly values computed from OC-CCI data for the period September 1997 - December 2013. Carbon-based size classes of phytoplankton: Fractional (\%) contributions of (a) picoplankton carbon, (b) nanoplankton carbon and (c) microplankton carbon to total phytoplankton carbon. Estimates of the concentrations of (d) picoplankton carbon, (e) nanoplankton carbon and (f) microplankton carbon in the surface in $\mathrm{mg} \mathrm{m}^{-3}$. 
440

441

442

443

444

445

446

447

448

449 whereas in the equatorial gyres it is below $0.5 \mathrm{mgC} \mathrm{m}^{-3}$ (Fig. $5 \mathrm{f}$ ).

450

451

452

453

454

455

456 457 respectively. whereas in the equatorial gyres it is below $0.5 \mathrm{mg}^{-3}(\mathrm{Fig} .5 \mathrm{f})$

ever, the range of pico-carbon may vary from $2 \mathrm{mgC} \mathrm{m}^{-3}$ to more than $100 \mathrm{mgC} \mathrm{m}^{-3}$ (Fig. $5 \mathrm{~d}$ ).

The stocks of nano-plankton carbon are $10-15 \%$ of total phytoplankton carbon in equatorial gyres, and go up to 40-45\% in the southern ocean, northern hemisphere and coastal oceans (Fig. 5b). These percentages account for $\sim 2-3 \mathrm{mg} \mathrm{m}^{-3}$ of nano-carbon in the equatorial gyres, and $\sim 10-30 \mathrm{mgC} \mathrm{m}^{-3}$ in the northern and southern oceans (Fig. 5e). The stocks of microcarbon, on the other hand, are estimated to be less than $20 \%$ in most of the equatorial and southern ocean, except the coastal regions, and in the northern hemisphere, where its percentage contribution goes up to 70-80\% (Fig. 5c). In the coastal oceans and northern hemisphere, the concentration of micro-plankton carbon is estimated to be in the range $20-30 \mathrm{mgC} \mathrm{m}^{-3}$,

The global distributions of the size-partitioned phytoplankton carbon can be spatially integrated over the mixed-layer depth to estimate their annual-mean stocks, which are $\sim 0.14 \mathrm{GtC}$ for picoplankton (with a monthly range of 0.13-0.16 GtC), $\sim 0.08 \mathrm{GtC}$ for nanoplankton (with a monthly range of $0.07-0.09 \mathrm{GtC}$ ) and $\sim 0.04 \mathrm{GtC}$ for microplankton (with a monthly range of $0.03-0.041 \mathrm{GtC}$ ) (Fig. 4c). These stocks of carbon in the three size classes constitute approximately $54 \%$ (with a monthly range of 53-62\%), 31\% (with a monthly range of 27-32\%) 56 and $15 \%$ (with a monthly range of $10-16 \%$ ) of the global stock of phytoplankton carbon, 457, respectively. 
458

459

460

461

462

463

464

465

466

467

468

469

470 471 on phytoplankton carbon).

472

473

474

475

476

477

478

\subsection{Sources and estimates of uncertainty}

The estimates of phytoplankton carbon from the bio-optical algorithm presented here would be subject to uncertainties from two sources: uncertainties associated with the remote sensing products (chlorophyll-a and phytoplankton absorption, and hence satellite-derived values of

$\xi)$; and the uncertainties in allometric parameterisation in the bio-optical model; but the two uncertainty sources are independent of each other. We consider an overall uncertainty in $\xi$ arising from the uncertainties in satellite chlorophyll-a and phytoplankton absorption (based on the uncertainty calculations by Roy et al., 2013). We then compute from Eq. (7) the total relative sensitivity of the estimated phytoplankton carbon (i.e, $\frac{\Delta C_{\text {total }}}{C_{\text {total }}}$ ), as a combined function of the individual relative sensitivities $\frac{\Delta \xi}{\xi}, \frac{\Delta a}{a}$, and $\frac{\Delta b}{b}$. In the following, we apply the above sensitivity analysis to understand the uncertainties in the estimation. The uncertainties presented below should be interpreted as model-based uncertainties; and not as those based on the in situ observations (which was not possible due to lack of the size-partitioned data

The overall uncertainties in the estimates of phytoplankton carbon due to $0-25 \%$ uncertainties in $\xi$ (chosen based on Roy et al., 2013) and $20 \%$ uncertainties in the allometric parameters $a$ and $b$ are presented on a contour map in Fig. (6a). The uncertainty level in phytoplankton carbon is typically $<30 \%$ over the range of $\xi$ typically encountered at sea, except for $\xi$ values between 3.5 and 4, where the uncertainties can amplify up to 80-90\% corresponding to $>20 \%$ uncertainty in satellite-derived $\xi$ values (Fig. 6a). In other words, for phytoplankton populations that are clearly dominated by either small cells (higher end of $\xi$ ) 

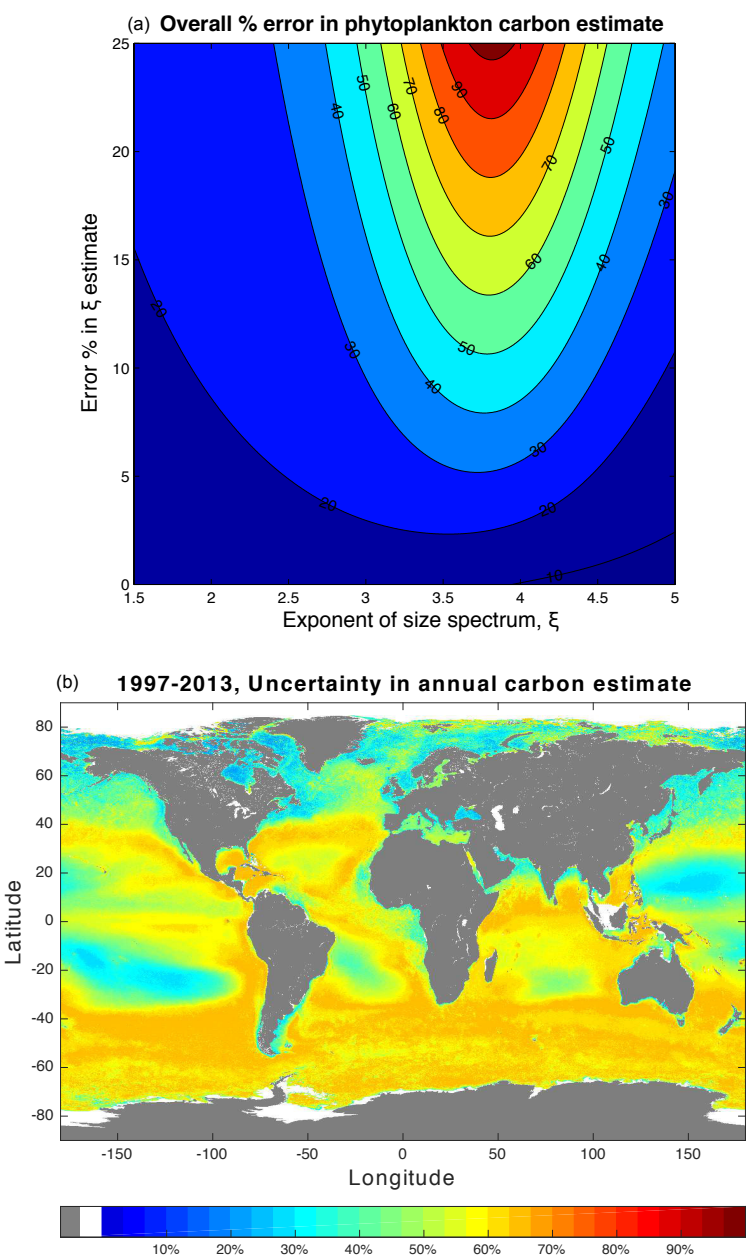

Figure 6: Level of uncertainties in phytoplankton carbon computed by the method proposed here. (a) Uncertainty in phytoplankton carbon estimates due to possible errors in estimating $\xi$ (the exponent of phytoplankton size spectrum) and $b$ (the exponent of allometric carbon relationship). The overall uncertainties in the estimates of phytoplankton carbon are shown over a possible uncertainty range $0-25 \%$ for $\xi$ and an uncertainty level $20 \%$ for $b$. (b) Propagated uncertainties in the estimates of phytoplankton carbon corresponding to $25 \%$ uncertainty in $\xi$ and 20\% uncertainty in $b$ over the global ocean for the period of 1997-2013. 
479

or large cells (lower end of $\xi$ ), the uncertainties in estimating phytoplankton carbon will be low (20-30\%), but, for populations with no obvious dominance by large or small cells, the uncertainties can be high $(>30 \%)$.

On the global map, the propagation of uncertainties in phytoplankton carbon corresponding to the higher ends of uncertainties in $\xi$ (say, 25\%), $a$ and $b$ (say, 20\%) is presented for 1997-2013 (Fig. 6b). In most of the Northern hemisphere, in the subtropical gyres and in the coasts, the uncertainties in phytoplankton carbon are within a range of $20-40 \%$ (Fig. $6 \mathrm{~b}$ ). However, uncertainties in the Southern Ocean, and parts of Atlantic Ocean can go up to $50-70 \%$ (Fig. 6b). The lower and upper levels of the annual stocks of phytoplankton carbon arising from regional-level uncertainties may vary between $0.12 \mathrm{GtC}$ and $0.35 \mathrm{GtC}$; and those for pico-, nano- and micro- carbon may vary in the ranges of $[0.07,0.2],[0.03,0.09]$ and $[0.01$ 0.04] GtC, respectively (Fig. 7). The monthly variations of the stocks are also remarkable: the possibility exists of pico-carbon stock being larger or smaller than the default estimates, whereas for microplankton-carbon, the uncertainties tend to lower the estimates, as evident when taking into account regional uncertainties in phytoplankton carbon (Fig. 7).

\section{Concluding remarks}

Estimates of total concentration of carbon in phytoplankton and its fractions in various phytoplankton size classes from satellite-remote sensing can provide valuable information for ocean biogeochemical and carbon-cycle research. However, the work in this direction has been hampered by the absence of a remote-sensing signal that can be related directly to phytoplankton 
(a) Climatology 1997-2013: uncertainty in Pico C

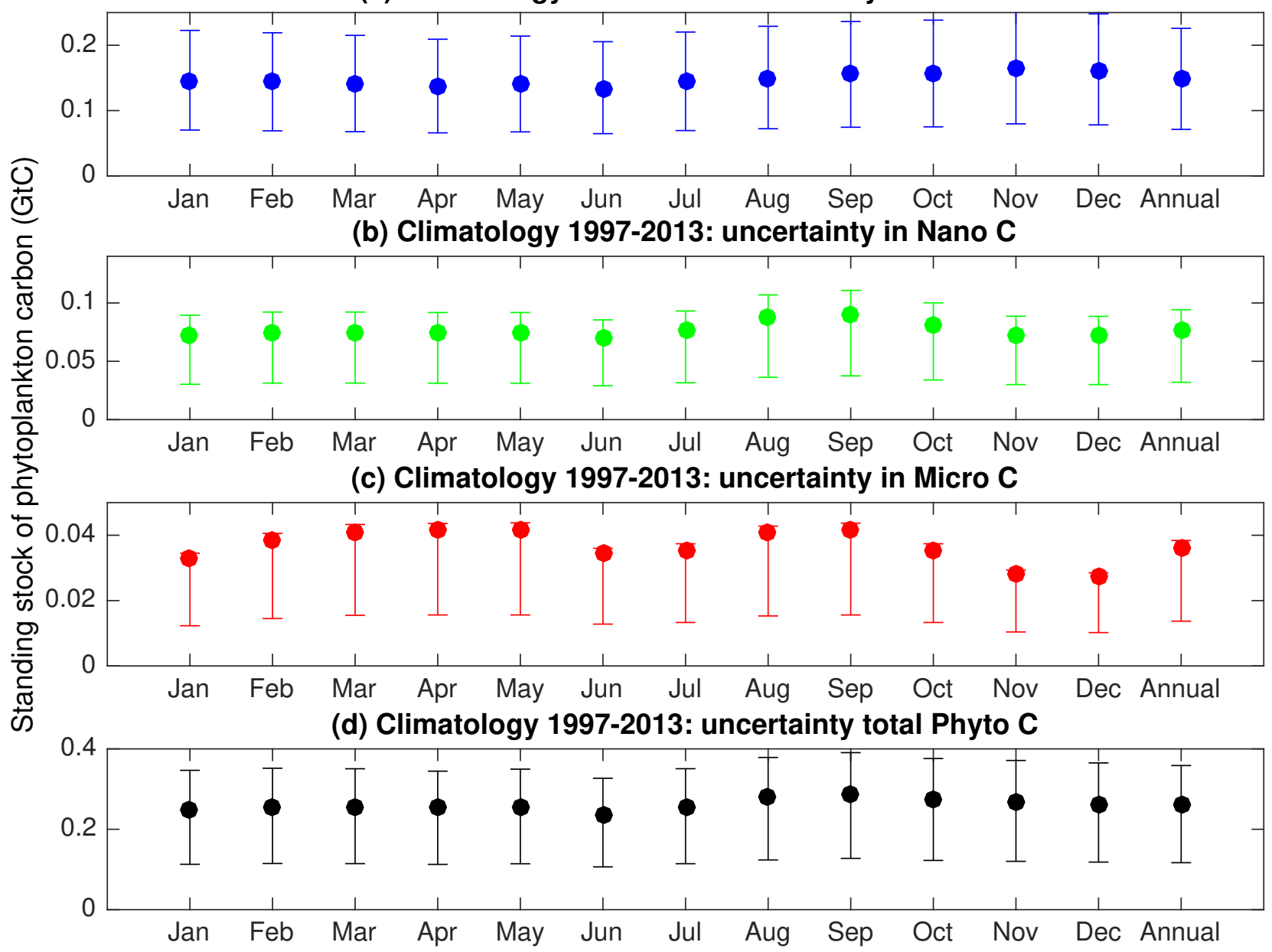

Figure 7: Estimates of uncertainties in the monthly and annual standing stocks of phytoplankton carbon. Monthly and annual climatologies of the standing stocks of (a) picoplankton carbon, (b) nanoplankton carbon, (c) microplankton carbon and (d) total phytoplankton carbon, plotted along with their corresponding uncertainty ranges (represented by vertical error bars) estimated assuming possible uncertainties in $\xi$ and $b$ parameterisation as in Fig. 6 
499

500

501

502

503

504

505

506

507

508

509

510

511

512

513

514

515

516

517

519

518 by the other methods that are available at present (Behrenfeld et al., 2005; Kostadinov et al.,

carbon. Only a small number of studies have addressed this problem, and all the methods

proposed so far (Behrenfeld et al., 2005; Kostadinov et al., 2016; Stramski et al., 2008) have

relied on relating POC to back-scattering or to remote-sensing reflectance, and then ascribing

a fixed fraction of POC to phytoplankton. Though these approaches have met with reasonable

success, their weakness lies in the natural variability in the ratio of phytoplankton carbon to

POC, which the algorithms cannot account for.

Here we present a novel bio-optical algorithm that uses the absorption coefficient of phyto-

plankton from remote sensing along with the allometric relationship of cellular carbon content

to compute carbon-to-chlorophyll ratio, the standing stocks of phytoplankton carbon, and the

carbon-based proportions of phytoplankton size classes, in the global ocean. The basis of the

method is the bio-optical algorithm developed by Roy et al. (2013) to compute the exponent

of the phytoplankton size spectrum and the chlorophyll proportions at various size classes

from the absorption coefficient of phytoplankton in the red part of the absorption spectrum.

Extending the method of Roy et al. (2013), we have derived analytical expressions for combin-

3 ing phytoplankton absorption from remote sensing with the allometric relationship between

cell size and phytoplankton carbon. The new expressions enable computation of phytoplank-

ton carbon from satellite remote sensing based on the bio-optical fingerprints of the living

6 phytoplankton alone. By design, this absorption-based method does not rely on a systematic

17 relationship between phytoplankton carbon and POC (such as a constant ratio), as required

19 2016). Instead, by combining the estimates of phytoplankton carbon, based on the absorption 
520

coefficient of pigment-containing phytoplankton cells (presented here), with the estimates of POC from back-scattering or remote-sensing reflectances (Behrenfeld et al., 2005), we can arrive at independent estimates of the ratio of phytoplankton carbon to POC. Such estimates would be an immediate application of the method proposed here.

We have used the new method to compute phytoplankton carbon in the global ocean on a monthly basis for the 1997-2013 period using OC-CCI time series data, and computed monthly climatologies of the standing stock of phytoplankton carbon in the mixed layer, and their annual averages. The new results are of the same order of magnitude, and comparable with, those reported earlier (Behrenfeld et al., 2005; Kostadinov et al., 2016; Stramski et al., 2008), though there are regional and seasonal differences. We have provided the RMSE and bias of the estimates with respect to the in situ measurements of the picopankton carbon, but due to the unavailability of in situ data, we have been unable to estimate the uncertainties, RMSE or bias for other phytoplankton size classes (e.g., micro- or nano- phytoplannkton). We also recognize that, as additional data become available, it would be interesting and useful to carry out extensive inter-comparisons among the various methods for estimating phytoplankton carbon.

With the availability of a variety of satellite-derived products, it has become increasingly important to understand and quantify uncertainties associated with these products. For example, the Global Climate Observing System (GCOS) has provided requirements for accuracy in ocean-colour data that can be used for climate studies (GCOS, 2011). Because our method for estimation of carbon is semi-analytical, it is possible, as shown here, to quantify 
541

\section{${ }_{558}$ Acknowledgements}

analytically the uncertainties in carbon estimates, provided that the uncertainties in satellitederived chlorophyll and absorption coefficient are known. For illustration, we have provided estimates of the uncertainties corresponding to $30 \%$ overall uncertainty (GCOS requirement) in the satellite input, and we have identified the oceanographic regions where the carbon estimates will be less (or more) sensitive to uncertainties in the inputs. These calculations also provide insight into the error characteristics of phytoplankton carbon estimated by our method, and suggest that the errors do not generally amplify, and that they become less for more accurate retrievals of the satellite-based inherent optical properties. Another source of uncertainty is the allometric parametrisation, and any change in the allometric parameters would alter our estimates of phytoplankton carbon (as shown in the sensitivity results). How-

ever, implementation of any improved allometric parametrisation within this method would be straight forward. Finally, we note that the uncertainties in the estimates of carbon in the coastal oceans and at high latitudes may be high due to several reasons, e.g., high concentration of CDOM, solar zenith angles, clouds or ice; and so this method, like many other ocean colour algorithms, will be generally applicable to open oceans. Further investigations should address its applicability to optically complex waters, and oceanic regions with complex phytoplankton community structure, e.g., blooms of large chain-forming diatoms.

We acknowledge the project team of Ocean Colour Climate Change Initiative for generating and sharing the merged datasets on chlorophyll and inherent optical properties. We also 
561 567 have improved the paper.

acknowledge the mission scientists and Principal Investigators and everyone associated with compilation of the MAREDAT dataset, and for making the data freely available. The research was funded by the European Space Agency's Scientific Exploitation of Operational Missions Project Pools of Carbon in the Ocean (POCO). The work also benefited from the support of the National Centre for Earth Observation (NCEO) of Natural Environment Research Council, UK. The valuable comments and suggestions made by three anonymous reviewers

\section{References}

Behrenfeld, M. J., Boss, E., Siegel, D. A. and Shea, D. M. (2005), 'Carbon-based ocean productivity and phytoplankton physiology from space', Global biogeochemical cycles $\mathbf{1 9}(1)$.

Belo Couto, A., Brotas, V., Mélin, F., Groom, S. and Sathyendranath, S. (2016), 'Intercomparison of oc-cci chlorophyll-a estimates with precursor data sets', International Journal of Remote Sensing 37(18), 4337-4355.

Brewin, R. J., Sathyendranath, S., Müller, D., Brockmann, C., Deschamps, P.-Y., Devred, E., Doerffer, R., Fomferra, N., Franz, B., Grant, M. et al. (2015), 'The ocean colour climate change initiative: Iii. a round-robin comparison on in-water bio-optical algorithms', Remote Sensing of Environment 162, 271-294.

Buitenhuis, E. T., Li, W. K., Vaulot, D., Lomas, M. W., Landry, M., Partensky, F., Karl, D., 
Ulloa, O., Campbell, L., Jacquet, S. et al. (2012), 'Picophytoplankton biomass distribution in the global ocean', Earth System Science Data 4(1), 37-46.

Carder, K. L., Chen, F., Lee, Z., Hawes, S. and Kamykowski, D. (1999), 'Semianalytic moderate-resolution imaging spectrometer algorithms for chlorophyll a and absorption with bio-optical domains based on nitrate-depletion temperatures', Journal of Geophysical Research-Oceans 104(C3), 5403-5421.

DuRand, M. D., Olson, R. J. and Chisholm, S. W. (2001), 'Phytoplankton population dynamics at the bermuda atlantic time-series station in the sargasso sea', Deep Sea Research Part II: Topical Studies in Oceanography 48(8), 1983-2003.

Duyens, L. (1956), 'The flattering of the absorption spectrum of suspensions, as compared to that of solutions', Biochimica et Biophysica Acta 19, 1-12.

Eppley, R. W., Chavez, F. P. and Barber, R. T. (1992), 'Standing stocks of particulate carbon and nitrogen in the equatorial pacific at 150 w', Journal of Geophysical Research: Oceans 97(C1), 655-661.

Falkowski, P. (2012), 'The power of plankton', Nature 483, S17-S20.

Field, C. B., Behrenfeld, M. J., Randerson, J. T. and Falkowski, P. (1998), 'Primary production of the biosphere: integrating terrestrial and oceanic components', Science 281(5374), 237-240.

GCOS, G. (2011), 'Systematic observation requirements for satellite-based products for climate. 2011 update supplemetnatl details to the satellite 39 based component og the imple- 
mentation plan for the global observing system for climate in support of the unfccc (2010 update)', Tech. rep., World Meteorological Organisation (WMO), 7 bis, avenue de la Paix, CH- 1211 Geneva 2, Switzerland.

Geider, R. J. (1987), 'Light and temperature dependence of the carbon to chlorophyll a ratio in microalgae and cyanobacteria: implications for physiology and growth of phytoplankton', New Phytologist 106(1), 1-34.

Geider, R. J., MacIntyre, H. L. and Kana, T. M. (1998), 'A dynamic regulatory model of phytoplanktonic acclimation to light, nutrients, and temperature', Limnology and Oceanography 43(4), 679-694.

Gundersen, K., Orcutt, K. M., Purdie, D. A., Michaels, A. F. and Knap, A. H. (2001), 'Particulate organic carbon mass distribution at the bermuda atlantic time-series study (bats) site', Deep Sea Research Part II: Topical Studies in Oceanography 48(8), 1697-1718.

IOCCG, ed. (2014), Phytoplankton functional types from Space., number 15, International Ocean-Colour Coordinating Group, Reports of the International Ocean-Colour Coordinating Group (IOCCG).

Kostadinov, T., Milutinovic, S., Marinov, I. and Cabré, A. (2016), 'Carbon-based phytoplankton size classes retrieved via ocean color estimates of the particle size distribution', Ocean Science Discussions 12, 561-575.

7 Marañón, E. (2008), 'Inter-specific scaling of phytoplankton production and cell size in the field', Journal of Plankton Research 30(2), 157-163. 
619

620

621

622

623

624

625

626

627

628

629

630

631

632

633

634

635

636

637

638

Marañón, E., Cermeño, P., López-Sandoval, D. C., Rodríguez-Ramos, T., Sobrino, C., HueteOrtega, M., Blanco, J. M. and Rodríguez, J. (2013), 'Unimodal size scaling of phytoplankton growth and the size dependence of nutrient uptake and use', Ecology letters 16(3), 371-379.

Maranón, E., Cermeno, P., Rodriguez, J., Zubkov, M. V. and Harris, R. P. (2007), 'Scaling of phytoplankton photosynthesis and cell size in the ocean', Limnol. Oceanogr 52(5), 21902198.

Menden-Deuer, S. and Lessard, E. J. (2000), 'Carbon to volume relationships for dinoflagellates, diatoms, and other protist plankton', Limnology and Oceanography 45(3), 569-579.

Müller, D., Krasemann, H., Brewin, R. J., Brockmann, C., Deschamps, P.-Y., Doerffer, R., Fomferra, N., Franz, B. A., Grant, M. G., Groom, S. B. et al. (2015), 'The ocean colour climate change initiative: Ii. spatial and temporal homogeneity of satellite data retrieval due to systematic effects in atmospheric correction processors', Remote Sensing of Environment $162,257-270$.

Oubelkheir, K., Claustre, H., Sciandra, A. and Babin, M. (2005), 'Bio-optical and biogeochemical properties of different trophic regimes in oceanic waters', Limnology and oceanography 50(6), 1795-1809.

Peters, R. H. (1983), The Ecological Implications of Body Size, Cambridge University Press, Cambridge.

Redalje, D. and Laws, E. (1981), 'A new method for estimating phytoplankton growth rates and carbon biomass', Marine Biology 62(1), 73-79. 
639

640

641

642

643

644

645

646

647

648

649

650

651

652

653

654

655

656

657

658

Roy, S., Sathyendranath, S., Bouman, H. and Platt, T. (2013), 'The global distribution of phytoplankton size spectrum and size classes from their light-absorption spectra derived from satellite data', Remote Sensing of Environment 139, 185-197.

Roy, S., Sathyendranath, S. and Platt, T. (2011), 'Retrieval of phytoplankton size from biooptical measurements: theory and applications', Journal of The Royal Society Interface 8(58), 650-660.

Sathyendranath, S., Brewin, R., Brockmann, C., Brotas, V., Ciavatta, S., Chuprin, A., Couto, A., Doerffer, R., Dowell, M., Grant, M., Groom, S., Horseman, A., Jackson, T., Krasemann, H., Lavender, S., Martinez Vicente, V., Mélin, Moore, T., Müller, D., Regner, P., Roy, S., Steinmetz, F., Swinton, J., Taberner, M., Thompson, A., Valente, A., Zühlke, M., Brando, V., Feldman, G., Franz, B., Frouin, R., Gould, Jr, R., Hooker, S., Kahru, M., Mitchell, M., Muller-Karger, F., Sosik, H., Voss, K., Werdell, J. and Platt, T. (2016), 'Creating an ocean-colour time series for use in climate studies: the experience of the ocean-colour climate change initiative', Unpublished manuscript.

Sathyendranath, S., Stuart, V., Nair, A., Oka, K., Nakane, T., Bouman, H., Forget, M.-H., Maass, H. and Platt, T. (2009), 'Carbon-to-chlorophyll ratio and growth rate of phytoplankton in the sea', Marine Ecology Progress Series 383(7), 73-84.

Schmidtko, S., Johnson, G. C. and Lyman, J. M. (2013), 'MIMOC: A global monthly isopycnal upper-ocean climatology with mixed layers', Journal of Geophysical Research: Oceans $\mathbf{1 1 8}(4), 1658-1672$. 
659

660 ${ }_{661} \quad 1$ ', Limnology and Oceanography 23(6), 1256-1263.

662

663

664

665

666

667

668

669

670

671

672

673 106(C9), 19939-19956.

Sieburth, J. M., Smetacek, V. and Lenz, J. (1978), 'Pelagic ecosystem structure: Heterotrophic compartments of the plankton and their relationship to plankton size fractions

Stramski, D., Reynolds, R. A., Babin, M., Kaczmarek, S., Lewis, M. R., Röttgers, R., Sciandra, A., Stramska, M., Twardowski, M., Franz, B. et al. (2008), 'Relationships between the surface concentration of particulate organic carbon and optical properties in the eastern south pacific and eastern atlantic oceans', Biogeosciences 5(1), 171-201.

Strathmann, R. (1967), 'Estimating the organic carbon content of phytoplankton from cell volume or plasma volume', Limnology and Oceanography 12(3), 411-418.

Taylor, K. E., Stouffer, R. J. and Meehl, G. A. (2012), 'An overview of cmip5 and the experiment design', Bulletin of the American Meteorological Society 93(4), 485-498.

Vidussi, F., Claustre, H., Manca, B. B., Luchetta, A. and Marty, J.-C. (2001), 'Phytoplankton pigment distribution in relation to upper thermocline circulation in the eastern mediterranean sea during winter', Journal of Geophysical Research: Oceans (1978-2012) 